\title{
The Effect of Group 5 (V, Nb, Ta) Additions on Precipitation in Al-Sc Alloys
}

\author{
Keith E. Knipling ${ }^{1}$
}

${ }^{1 .}$ U. S. Naval Research Laboratory, Multifunctional Materials Branch, Washington, DC 20375

Al-Sc alloys, strengthened by nanoscale $\mathrm{Al}_{3} \mathrm{Sc}\left(\mathrm{L}_{2}\right.$ structure) precipitates, have excellent coarsening and creep resistance to $300{ }^{\circ} \mathrm{C}$ [1,2], and can be improved up to $400{ }^{\circ} \mathrm{C}$ with ternary additions of the neighboring Group 4 elements, $\mathrm{Ti}$ [3] $\mathrm{Zr}$ [4,5] or Hf [6]. These ternary solutes have a much smaller diffusivity than $\mathrm{Sc}$ [1], resulting in $\mathrm{Al}_{3} \mathrm{Sc}_{1-x} \mathrm{M}_{x}(\mathrm{M}=\mathrm{Ti}, \mathrm{Zr}$, or $\mathrm{Hf})$ precipitates with a Sc-rich core enveloped in a Zr, Ti, or Hf-enriched shell. These slower-diffusing atoms limit coarsening and, since they substitute for $\mathrm{Sc}$ in the precipitates, can also reduce the relatively high cost of Sc additions.

The Group 5 elements in the periodic table $(\mathrm{M}=\mathrm{V}, \mathrm{Nb}$, or Ta) may also be beneficial alloying additions to Al-Sc alloys. They each form an $\mathrm{Al}_{3} \mathrm{M}$ trialuminide and also exhibit some solubility in $\mathrm{Al}_{3} \mathrm{Sc}$ [7], and are anticipated to be much slower diffusers than $\mathrm{Ti}, \mathrm{Zr}$, or $\mathrm{Hf}$ [1], potentially providing better thermal stability than Al-Sc-Ti, Al-Sc-Zr, or Al-Sc-Hf alloys. This study investigates the nanostructures and compositions of $\mathrm{Al}_{3} \mathrm{Sc}_{1-x} \mathrm{M}_{x}$ precipitates formed during isochronal aging in (i) highly supersaturated Al$\mathrm{Sc}-\mathrm{V}-(\mathrm{V} / \mathrm{Nb} / \mathrm{Ta})$ alloys produced by melt-spinning and (ii) dilute Al-Er-Sc-(V/Nb/Ta) made by arc melting. The alloys are evaluated by Vickers microhardness, electrical conductivity, bright-field and darkfield transmission electron microscopy (TEM, FEI Tecnai $\mathrm{G}^{2} 30$ operating at $200 \mathrm{kV}$ ), and atom-probe tomography (APT, Cameca LEAP 4000x Si).

Figure 1 displays $\mathrm{Al}_{3} \mathrm{Sc}_{1-x} \mathrm{M}_{x}$ precipitates, and their compositions (as measured by proxigrams [8]), formed after isochronal aging to 400 and $500{ }^{\circ} \mathrm{C}$. As observed in prior APT studies on Al-Sc-Ti, Al-Sc-Zr, and Al-Sc-Hf alloys [3-6], the $\mathrm{V}, \mathrm{Nb}$, or Ta atoms constitute a small fraction of the $\mathrm{Al}_{3} \mathrm{Sc}$ precipitates. The degree of partitioning of the Group 5 solutes is, however, much less than that observed with Group 4 additions, indicating the Group 5 solutes have smaller diffusivities, as expected. In Figure 1, only V segregates appreciably to the precipitates, suggesting that it is a faster diffuser than $\mathrm{Nb}$ or $\mathrm{Ta}$, and forms $\mathrm{a} \sim 1 \mathrm{~nm}$ thick shell with a peak concentration of $\sim 2.75$ at. $\% \mathrm{~V}$.

Similar trends are observed in the dilute Al-Er-Sc-Zr-(V/Nb/Ta) alloys, where the Group 5 additions have a minor effect on the observed microhardness and precipitation behavior (Figure 2). These properties will be correlated to the precipitate size and compositions, as measured by TEM and APT.

\section{References:}

[1] K Knipling et al, International Journal of Materials Research 97 (2006), p. 246.

[2] J Royset and N Ryum, International Materials Reviews 50 (2005), p. 19.

[3] M van Dalen et al, Acta Materialia 53 (2005), p. 4225

[4] C Fuller et al, Acta Materialia 51 (2003), p. 4803.

[5] C Fuller and D Seidman, Acta Materialia 53 (2005), p. 5415.

[6] H Hallem et al, Materials Science and Engineering A 421 (2006), p. 154.

[7] Y Harada and D Dunand, Materials Science and Engineering A 329 (2002), p. 686.

[8] O Hellman et al, Microscopy and Microanalysis 6 (2000), p. 437. 

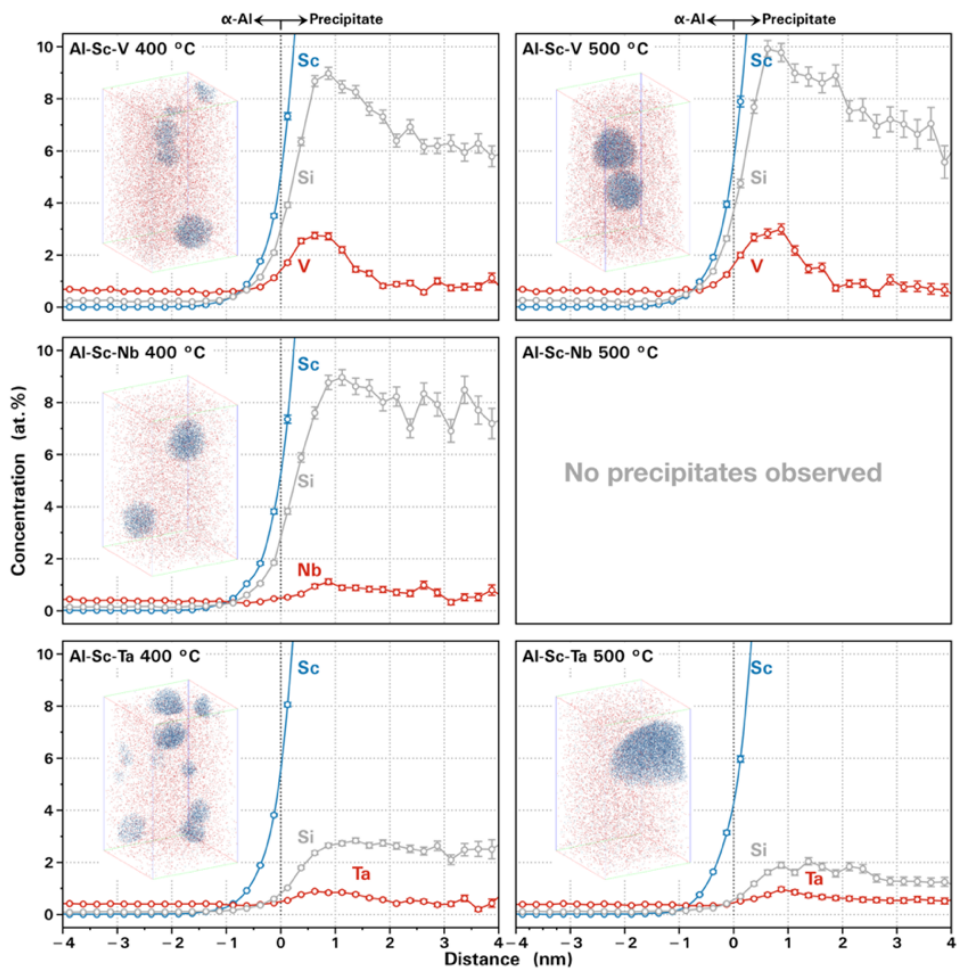

Figure 1. Proxigrams of the Al-Sc-V, A-Sc-Nb, and Al-Sc-Ta alloys isochronally aged to 400 and 500 ${ }^{\circ} \mathrm{C}$. Inset are $15 \times 15 \times 50 \mathrm{~nm}^{3} \mathrm{APT}$ reconstructions, with each $\mathrm{Sc}$ atom represented as a blue pixel, $\mathrm{V} / \mathrm{Nb} / \mathrm{Ta}$ atoms with red pixels, and $\mathrm{Si}$ atoms with gray pixels (Al atoms are not shown for clarity).
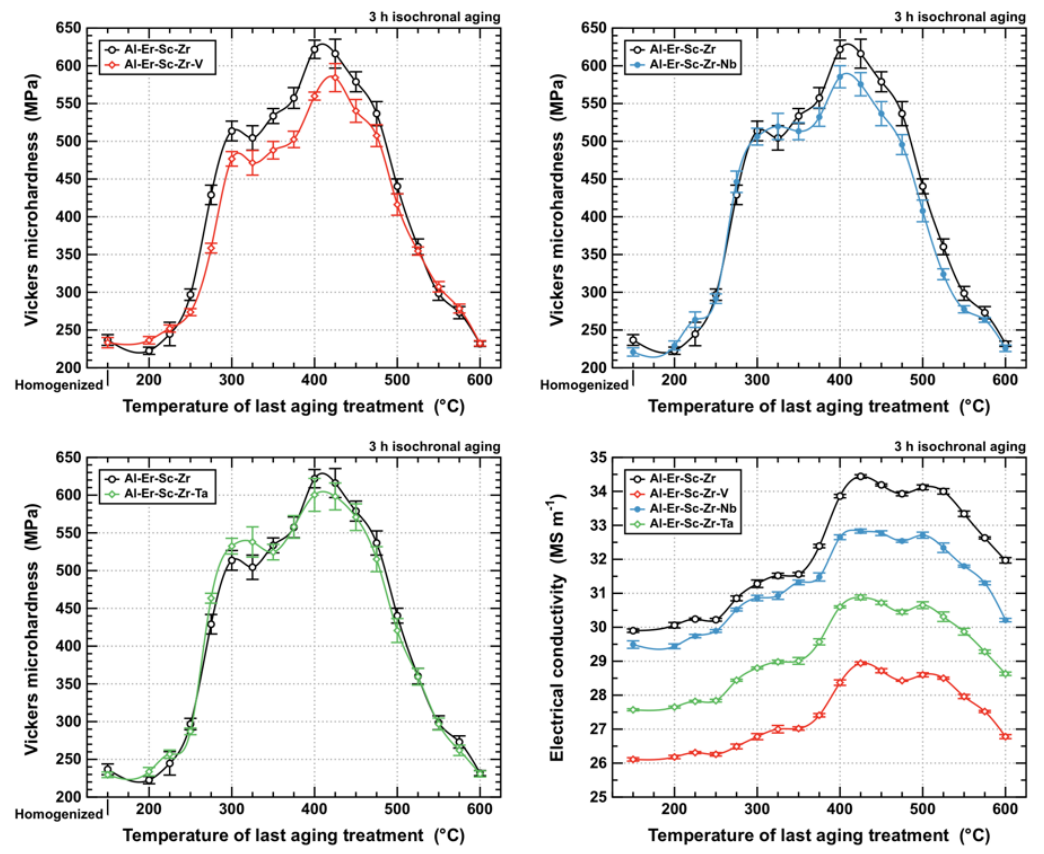

Figure 2. Vickers microhardness and electrical conductivity evolution during isochronal aging ( $3 \mathrm{~h}$ at each temperature) of the Al-Er-Sc-Zr and Al-Er-Sc-Zr-(V,Nb,Ta) alloys. 